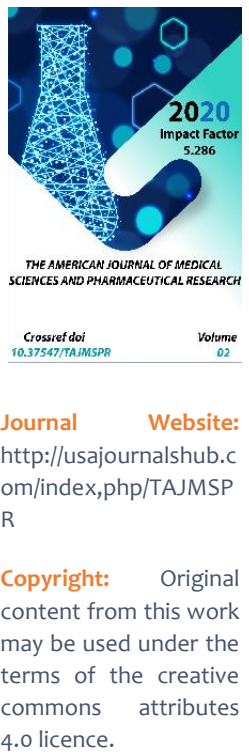

\section{The Use Of Daily Continuous Glucose Monitoring (Chmg) In Clinical Practice}

\author{
Narbaev Abduhamid Namazovich \\ P.h.D. Assistant Department Of Internal Medicine With Endocrinology, Samarqand State \\ Medical Institute,Samarqand, Republik Of Uzbekistan \\ Togaeva Gulnora Siddiqovna \\ Assistant Department Of Internal Medicine With Endocrinology, Samarqand State Medical \\ Institute,Samarqand, Republik Of Uzbekistan \\ Davranova Aziza Davranovna \\ Assistant Department Of Internal Medicine With Endocrinology, Samarqand State Medical \\ Institute,Samarqand, Republik Of Uzbekistan
}

\title{
ABSTRACT
}

Type 1 diabetes mellitus is a disease in which the highest rates of premature mortality and early disability of patients are observed, which is caused by the onset of the disease at an early age, the instability of the course of type 1 diabetes and the threat of acute and chronic complications. The goals of type 1 diabetes mellitus treatment are its compensation, prevention of the risk of complications when normoglycemia is reached and stabilized.

\section{KEYWORDS}

Diabetes mellitus, glucose, glycemia, self-monitors, insulin pump, glucated hemoglobin

\section{INTRODUCTION}

Relevance of the problem:. Diabetes mellitus in recent decades has been one of the first priorities of national health systems in all countries of the world, due to the high prevalence of this pathology and the growth of socio-economic losses associated with the development of severe disabling complications. In 2014, the number of patients with diabetes mellitus in the world, according to WHO experts, amounted to more 
than 360 million people, by 2030, it is expected to increase the number of patients to 480 million people. Self-monitoring of blood glucose is the primary way to control and manage diabetes. The current ADA (American Nutritional Association) recommendations imply that a patient with diabetes mellitus self-monitors blood glucose levels at least 4 times a day (3 times before meals and 1 time before bedtime).

Target: The aim of this work was to develop a continuous monitoring system (LMWH) of blood glucose in the management of type 1 diabetes mellitus using a pump. The CGM system was the first device approved by the FDA for three-day monitoring.

\section{MATERIALS AND RESEARCH METHODS}

The study was carried out on the basis of the Department of Endocrinology at the Samarkand Regional Endocrinological Dispensary. The study included 31 patients with type 1 diabetes mellitus, 36\% (n-12) men and $64 \%(n-19)$ women. The duration of the disease ranged from 6 months to 25 years (on average, $13.24+2.59$ years). The patients' age ranged from 15 to 45 years (average $29+3.26$ years). Pear 1 - patients who received insulin therapy in the mode of continuous subcutaneous insulin administration using an insulin pump (9 person). Pear 2 (control) patients who continued to receive a combination of insulin glargine (Lantus) plus ultrashort-acting human insulin analogues (22 people). The presence of complications of diabetes mellitus was determined according to the data of narrow specialists, as well as on the basis of biochemical blood tests. The inclusion criteria were: an established diagnosis of type 1 diabetes mellitus in the stage of decompensation, the presence of motivation and the ability to follow the doctor's recommendations.

\section{RESULTS AND DISCUSSION}

Hyperglycemic and hypoglycemic fluctuations were assessed in detailed analysis. The variability of glycemia significantly decreased: the duration of normoglycemia one year after the start of pump therapy increased from 21.6 $+0.3 \%$ to $87.3+0.35 \%$ of the measurement time ( $p<0.05)$. the duration of hypoglycemia decreased from $3.5+0.15 \%$ to $1.8+0.15 \%(p>$ $0.05)$, and the duration of the periods of hyperglycemia decreased by 2 times from 74.9 $+0.43 \%$ to $10.9+0.22 \%(p<0.05)$ measurement time. The absolute number of peaks-fluctuations of glycemia, both hyperand gpoglycemic decreased from $6.61+0.16$ to $4.42+0.16(D 2.2: p<0.05)$ and from $3.81+$ 0.11 to $1.22+0.11$ (D2.63 $\mathrm{p}<0.05)$, respectively. Group 2, whose patients received conventional insulin therapy in a multiple-injection regimen, was considered as a comparison bulb, which made it possible to evaluate the advantages of different methods of insulin therapy. Therefore, a comparative analysis of the parameters of carbohydrate metabolism according to the data of selfcontrol and continuous daily monitoring in group 2 and their comparison with the corresponding indicators of group 1 was of particular interest. The average total glycemic value decreased from 10.81-0.04 to $9.04+0.04$ mmol / L ( $p<0.05)$, there was a significant decrease in the postprandial average glycemic value from $12.3+0.18$ to $9.92+0.18 \mathrm{mmol} / \mathrm{L}$ (p-0.05). The glycated hemoglobin (HbAlc) value decreased after 6 months. therapy, however, without reaching the target level, and amounted to $8.30+0.04 \%(w-0.21)$, but 1 year after the start of observation, the average HDAlc level in this group of patients again increased to $9.10-0.18 \%(m-0.03)$, which 
can partly be explained by a decrease in patient compliance and demonstrates the insufficient effectiveness of this method of insulin therapy. Daily fluctuations in glycemia according to the average values in group 2, as well as in group 1, did not fit within the established range of $3.9-10 \mathrm{mmol} / \mathrm{I}$, the target level of postprandial glycemia after 2 hours (glycemia less than $7.5-8.0 \mathrm{mmol} / \mathrm{l}$ ) was not achieved. Hyperglycemic and hypoglycemic excursions have been studied in detail. The variability of glycemia decreased, but to a lesser extent than in group 1: the duration of normoglycemia one year after the start of pump therapy increased from $26.8+0.54 \%$ to $80.30 .45 \%$ of the measurement time ( $p<0.05)$, the duration of hypoglycemia decreased from $3.6-0.13 \%$ to $2.8+0.12 \%(p>0.05)$, and the duration of periods of hyperglycemia decreased from $69.6+0.33 \%$ to $16.9+0.28 \%$ (p $<0.05)$ measurement time. The number of peaks-fluctuations of glycemia, both hyperand hypoglycemic, decreased from $6.84+0.2$ to $5.61+0.13(p<0.05)$ and from $4.91+0.11$ to $3.81+0.11(p<0.05)$, respectively. The study clearly demonstrated a more pronounced, statistically significant decrease in the hypoglycemic peaks of fluctuations against the background of insulin therapy in the Нпви mode, including at night, reaching a plateau of normoglycemia, an increase in the duration of the period of normoglycemia during the day during LUTS. Thus, in spite of the fact that both of the considered variants of insulin therapy made it possible to control the average level of glycemia during the day within the limits close to the established range (3.9-10.0 mmol L), however, it was the continuous subcutaneous administration of insulin that ensured greater stability of glycemia during days and achievement of target values for most parameters of carbohydrate metabolism.
Results and discussion. 1. The use of NPVI in patients with type 1 diabetes mellitus provides less variability in the level of glycemia due to a decrease in the number of peaks-fluctuations in comparison with the regimen of multiple insulin injections, reduces the duration of episodes of hypo- and hyperglycemia, and significantly increases the duration of the period of normoglycemia to $87.3 \%$ when monitored with using a continuous glycemic monitoring system (CGM) for 72 hours.

2. On the background of therapy with an insulin pump, the target HbAlc values were achieved in $42.8 \%$ of patients, $57.2 \%$ of patients showed a decrease in HbAlc levels. In patients on a regimen of repeated insulin injections, the HbAlc value also decreases, however, not reaching the target value.

\section{REFERENCES}

1. Ametov A. S. Prospects for the treatment of diabetes mellitus in the next 10 years. I Russian medical journal. -2005.-T. 13. Ne6. - P. 288-203

2. Ametov A.S., Avakova K.A.. An integrated approach to patient management, receiving insulin pump therapy. Russian Medical Journal. - 2007, vol. 15, No27, -C. 2050-2052

3. Balabolkin M.I., Petunina N.A., Telnova M.E., Klebanova E.M., Antonova K.V. "The role of insulin therapy in compensating for diabetes mellitus." // Russian Medical Journal. -2007, No25.-C.27.

4. Dedov II, Shestakova M.B. Algorithms for specialized medical care for patients with diabetes mellitus. Moscow, 2006

5. Tiselko A.V. Using a system of round-theclock glucose monitoring and pump insulin therapy in patients with diabetes. Lecture, 2005, St. Petersburg. 
6. American Diabetes Association.

Continuous Subcutaneous Insulin

Infusion. // Diabetes Care. -2005, Vol. 25, Suppl. 1.- P. 116

7. Aussedat B, Dupire-Angel $M$, Gifford R, Klein JC, Wilson GS, Reach G: Interstitial glucose concentration and glycemia: implications for continuous subcutaneous glucose monitoring. // Am J Physiol Endocrinol Metab. 2007, N 278. E716-E728

8. Fiallo-Scharer R; Diabetes Research in Children Network Study Group: Eightpoint glucose testing versus the continuous ghucose monitoring system in evaluation of glucemic control in type 1 diabetes. // J Clin Endocrinol Metab, No. 90.- P: 3387-3391, 2005

9. G. S. Togaeva, Clinical And Biochemical Parameters Of Patients With Type 2 Diabetes Who Were Trained At The School Of Self- Control. // JOURNAL OF BIOMEDICINE AND PRACTICE SPECIAL ISSUE-2. P-131-136, 2020 